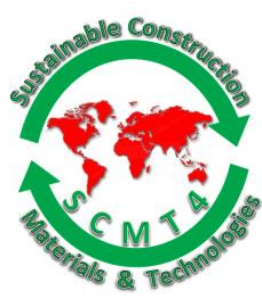

\title{
Experimental Study on Conservation and Preservation for Historical Architecture Using Plaster Finishing Material
}

\author{
Kentaro OKA $^{1 \mathrm{a}}$, Masaki TAMURA ${ }^{1 \mathrm{~b}}$, Hiroaki MARUYAMA ${ }^{1 \mathrm{c}}$, Junichi YOKOSHIMA ${ }^{1 \mathrm{~d}}$, \\ and Osamu GOTO ${ }^{1 e}$ \\ ${ }^{1}$ Department of Architecture, Graduate School of Engineering, Kogakuin Univ - Shinjuku-ku, Tokyo, 163- \\ 8677, JAPAN._19 Email: 〈dm15007@ns.kogakuin.ac.jp>, ${ }^{1 b}$ Email: 〈masaki-t@cc.kogakuin.ac.jp>, \\ ${ }^{l c}$ Email: <hiroakimaruyama@jcom.home.ne.jp>, ${ }^{l d}$ Email: <just.yokoshima@poem.ocn.ne.jp>, ${ }^{l e}$ Email: \\ <ogoto@cc.kogakuin.ac.jp>.
}

\begin{abstract}
Historical architectures and buildings have been built in Japan, often using plaster and mortar for surface finishing materials on the walls and ceilings regardless of structural types of masonry, wood and concrete. These plaster finishing materials are called Shikkui in Japanese, and the chemical ingredient is almost entirely $\mathrm{Ca}(\mathrm{OH})_{2}$. It resembles cement mortar and it becomes carbonized on the surface area during long term use. For example, the Himeji castle and the Gunkan Island (Battleship Island) of world heritage in Japan have used plaster materials as interior or exterior. Some of these historical architectures and buildings have been placed in harsh environment and occurred natural disaster frequently. Some historical architectures and buildings were damaged by the Great East Japan Earthquake 2011. There were some accidents caused by falling the ceiling, with dismal consequences for the buildings, and moreover lost the value of the building including the historical and traditional properties. Therefore, this study focused on the fundamental properties of strength and durability of plaster finishing materials applied to the ceiling. In this experiment, we produced many types of plaster specimens to evaluate the relationship between mix proportions and fundamental properties. These mix proportions have different contents of water, plaster, sand and natural plant fiber, and we conducted these experimental evaluations in detail. As these results in this study, it has been found that the mechanical strength of ceilings were related between plaster density within fiber and carbonated conditions. In addition, it would be expected to increase the potential fundamental properties and protect of authenticity by optimizing the use ratio of plaster materials.
\end{abstract}

\section{INTRODUCTION}

The traditional and historical architectures and buildings in Japan, a lot of stucco and plaster have been used as building finishing materials and their properties resemble ones of cement mortar. For example, they are used as a part of wall, roof, and ceiling as finishing materials similar to cement mortar. In Japan, stucco and plaster are called "Shikkui". Shikkui is a wet-mixing material made in fresh conditions, and which let's us freely construct building finishing materials. Therefore, plaster has a very high scalability and flexibility for use. In a famous example, Himeji Castle in Japan has a lot of applied plaster materials. 
On the other hand, Japan has a lot of disastrous earthquakes with. Therefore, many types of historical and traditional architectures and buildings have been often placed in harsh environmental conditions. In 2011 the Great East Japan Earthquake, a large number of buildings collapsed and the strength of ceiling boards using plaster finishing is seen as a possible problem. That is why, since the Great East Japan Earthquake, the owners of old buildings are concerned about the deterioration of the building components. Therefore the number of owners seeking to strengthen their building's components will increase. Moreover, in addition to preserving these historical and traditional architectures and buildings, it is also necessary to secure the safety from the standpoint of cultural and historical values. Therefore, we focused on these wooden lath and plaster ceiling that's used as a target of evaluation for saving the traditional architecture. In this study, a non-destructive inspection of an existing wooden lath and plaster ceilings, we evaluate the strength and other properties of plaster, and finally conduct the objectives to prolong the duration of life with safety conditions.

\section{DETAILS OF PROPERTIES ON THE TRADITIONAL BUILDINGS}

\section{Target of Architecture}

Table 1 shows the outline of the architecture. Morioka Bank was built at 1911 by a historical architect in Japan. The building is not currently being used as a bank, however, 100 years have passed since the building's construction, so it is a valuable part of Japanese architectural history. Therefore, it has been maintained from 2012 to 2016.

Table 1. Outline of a target architecture

\begin{tabular}{|c|l|}
\hline \multicolumn{1}{|c|}{ Architecture } & \multicolumn{1}{|c|}{ Morioka bank (Former head office) } \\
\hline \multicolumn{1}{c|}{ Location } & \multicolumn{1}{|c|}{ Nakayashikicho, Morioka-shi, Iwate, Japan } \\
\hline \multicolumn{1}{c|}{ Designer } & \multicolumn{1}{|c|}{ Kingo TATSUNO, Manji KASAI } \\
\hline \multirow{2}{*}{ Completion } & AD 1911 \\
\hline \multirow{2}{*}{ Structure } & Wall : British-style Brick \\
\hline \multirow{2}{*}{ Others } & Lath Plaster Ceiling Pratt truss \\
\cline { 2 - 3 } & (Surface of plaster finishing, Above wooden laths) \\
\hline
\end{tabular}

\section{Conditions of the Plaster Ceiling}

Plaster material is frequently used in old building's ceilings and walls. In general, the role of plaster ceilings are to transfer stress buffering between the lath and plaster. Therefore, it is important for the lath and plaster to be strongly adhered. This portion has been called "Plaster Key" in general and its role is to evaluate the mechanical properties of the plaster ceiling and wall. In Japan, this type of ceiling using plaster and mortar has been used from the early 1900s, and over a century has passed since the lath and plaster ceilings were developed, and at the same time the plaster has been frequently damaged in earthquakes.

Test Specimens of lath and plaster ceiling. Table 2 shows the details of lath and plaster ceiling specimens. The ceiling specimen is a square with 1.0 meter sides. These specimens were cut from a renovation ceiling of Morioka bank. The specimens "1911" and "1930s" are similar, although these specimens have been constructed in a different age. The one of the ceilings has been constructed at the 
same time as the construction of the bank at 1911. The other ceiling has been constructed when taller buildings were being constructed in the 1930s.

Experiment Methods of the Lath and Plaster ceiling. The lath and plaster ceiling specimens in the experiment were measured a cross-sectional length at first In order to evaluate the surface conditions by non-destructive inspection method. The hammering test was used to estimate the degree of deterioration by the hardness of the plaster finishing surface. Equation 1 shows the mechanical impedance value (HLD) by hammering test. The measurement points were obtained by dividing the ceiling plate specimens of a 2500 area by $50 \times 50$ cells. Finally, the relative intensity strength of the lath and plaster ceiling specimen were calculated.

$\mathrm{HLD}=\mathrm{v} / \mathrm{v}_{0} \times 1000$

$\mathrm{v}$ : Rebounding Speed of the Impactor, $\mathrm{v}_{0}$ : Percussion Speed of the Impactor

Table 2. Details of lath and plaster ceiling specimens

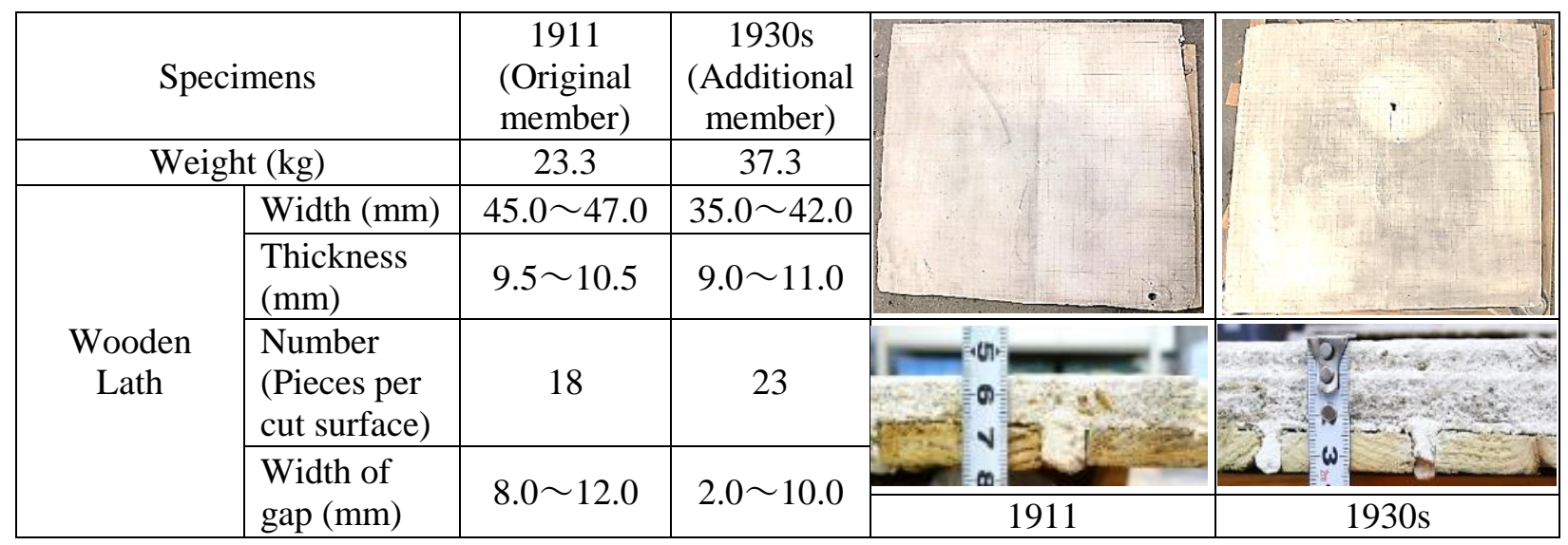

\section{Mechanical Systems of Lath and Plaster}

Figure 1 shows the concept of the stress transmission lath and plaster. Table 3 shows the material used and strength experiment types.

The mark A is shear strength transmitting the plaster load to wooden lath. The mark B is tensile strength to support the plaster load. The mark $\mathrm{C}$ is bending strength to resist the flaking and cracking.

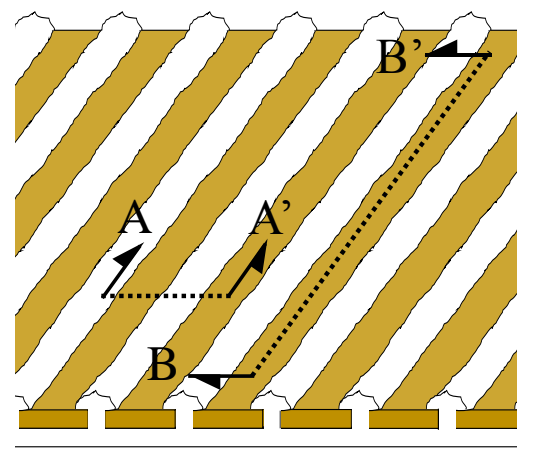

a) Lath plaster diagram

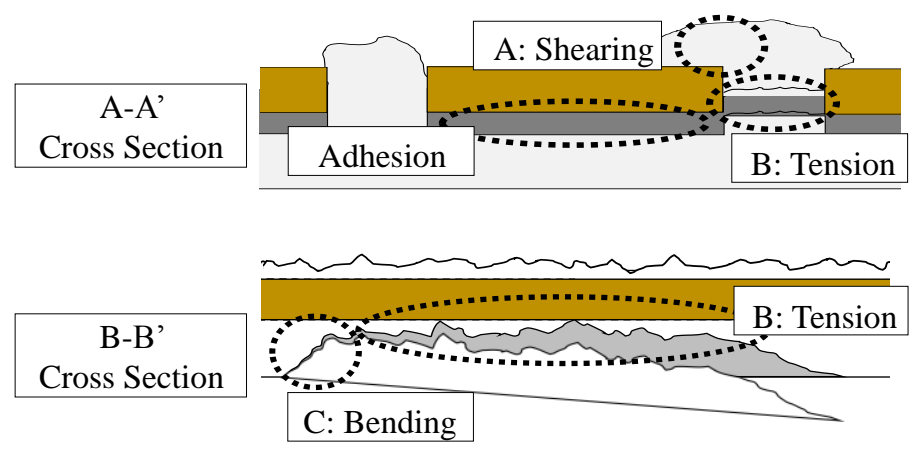

b) Virtual cross section

Figure 1. Mechanical Systems of Wooden Lath Plaster 
Table 3. Mixture and specimens of the Experiment

a) Mixture Proportion

\begin{tabular}{|c|c|c|}
\hline W/C $(\%)$ & $\mathrm{F} / \mathrm{V}(\%)$ & $\mathrm{S} / \mathrm{V}(\%)$ \\
\hline W: Water & \multicolumn{2}{|c|}{ The rate of the specimen volume } \\
C: Calcium Hydrate $\left(\mathrm{Ca}(\mathrm{OH})_{2}\right)$ & V: Volume, F: Fiber (straw), S: Sand (river) \\
\hline $75 \%, 90 \%$ & $0 \%, 2 \%, 4 \%$ & $0 \%, 20 \%, 40 \%$ \\
\hline
\end{tabular}

b) Specimen size of the Experiment

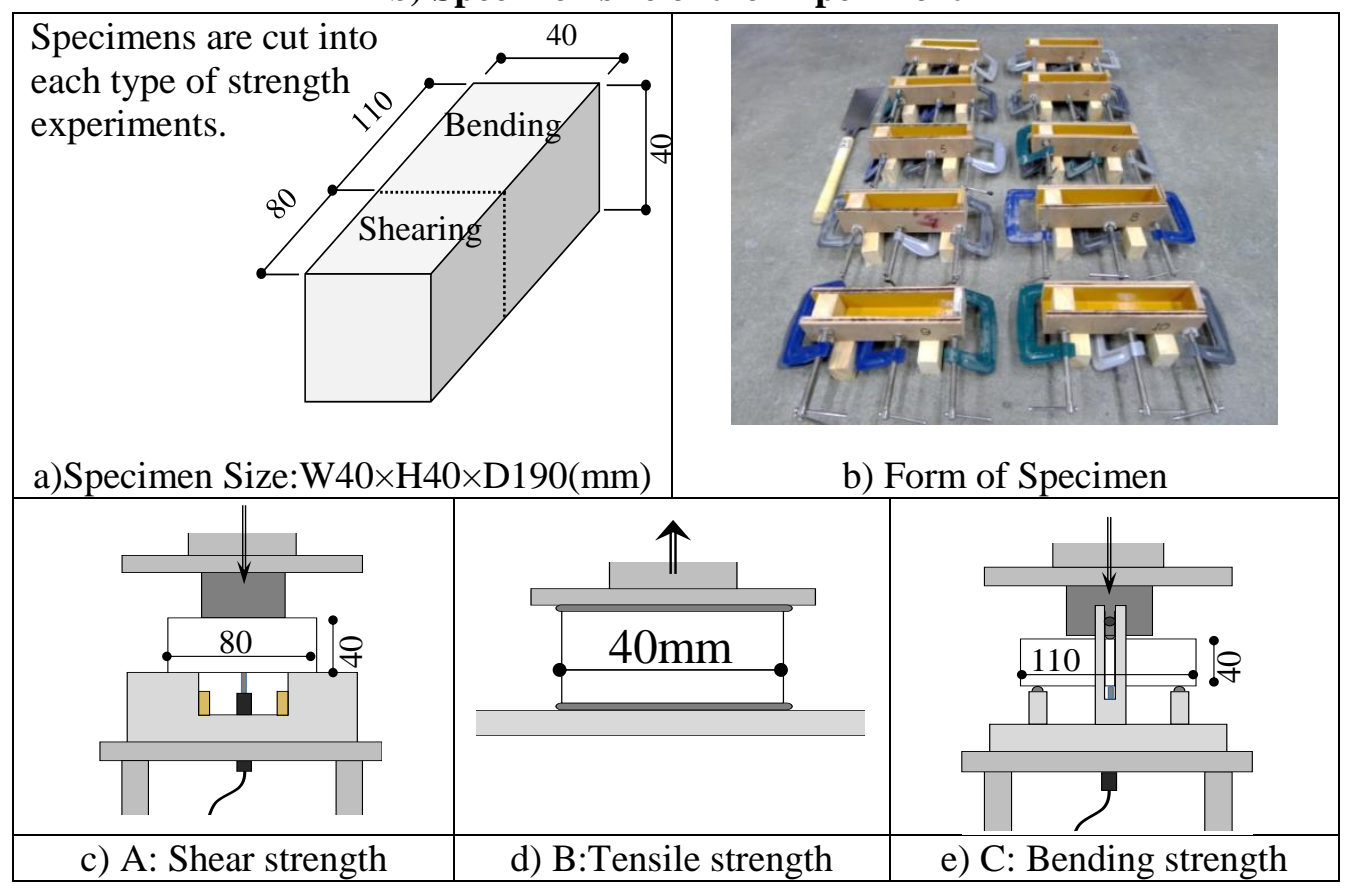

Peeling test of Plaster Layer. Figure 2 shows the divided lath and plaster ceiling specimens. The specimens could be evaluated to measure the strength conditions of the ceiling member. This specimen was made in suspending conditions of same environment of the ceiling. These strength tests were enforced after 24 days after placing fresh plaster. A tensile testing instrument was attached to the surface of the finishing plaster after curing. The tensile strength test was enforced to pull plaster against the wood lath and record the peeling resistance in maximum load, the plaster deformation, and destruction pattern of plaster key.

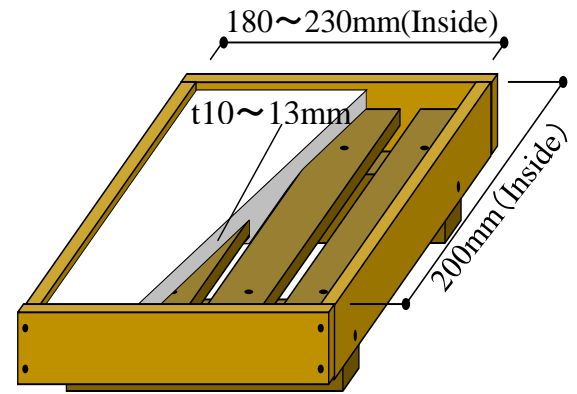

a) Specimen image

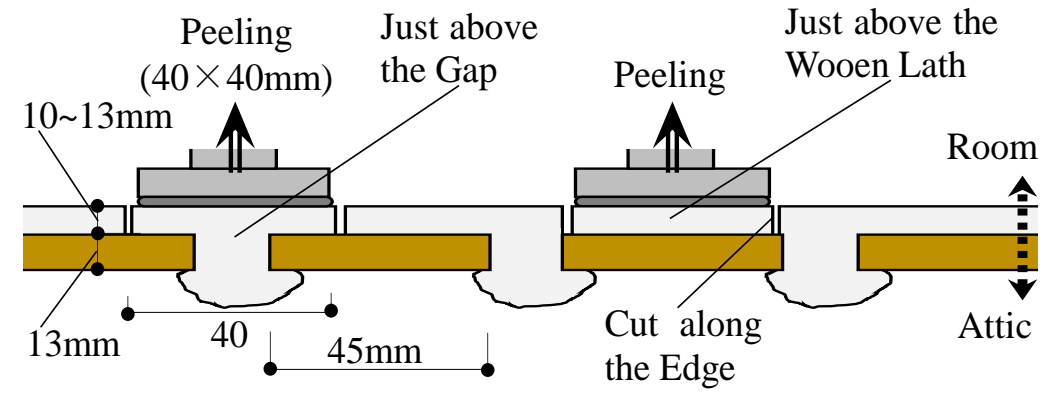

b) Cross section of Peeling Experiment

Figure 2. Lath and Plaster specimen and Peeling strength Experiment 
Repairing Method of lath plaster ceiling. Figure 3 shows the process of repairing lath plaster ceiling. From the standpoint of preserving cultural values in architectures and buildings, it is important to set the requirment to leave the original material and member if possible. In addition, it is also necessary to improve both design needs and safety. In the case of lath and plaster ceiling, it is better to improve the cracking of the surface plaster by acrylic resin. The method of repairing this type of ceiling is to make a hole to the wood lath (a) from the top of the ceiling, to inject acrylic resin and twine rope to the hole (b), to add the resin to the hole (c), and finally to connect the wooden lath and plaster. The repairing method prevents the peeling and falling of the lath and plaster ceiling.

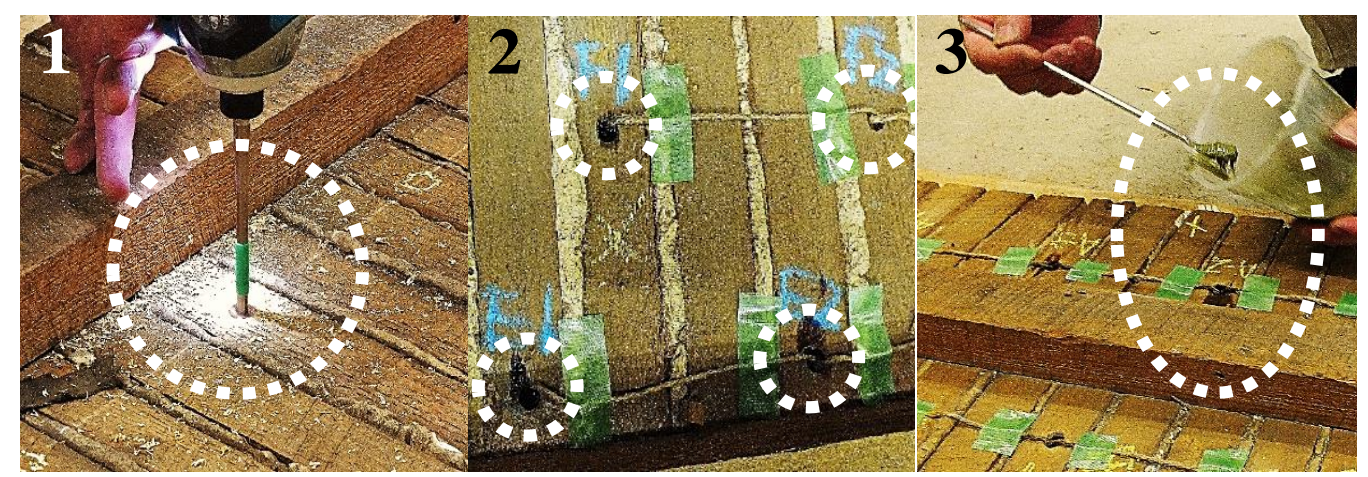

a) Make holes in the Lath b) Inject the acrylic resin and twine rope c) Add the resin to the hole

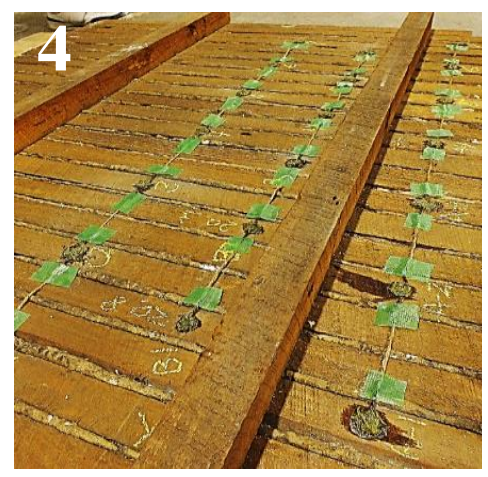

d) Connecting the wood lath and plaster

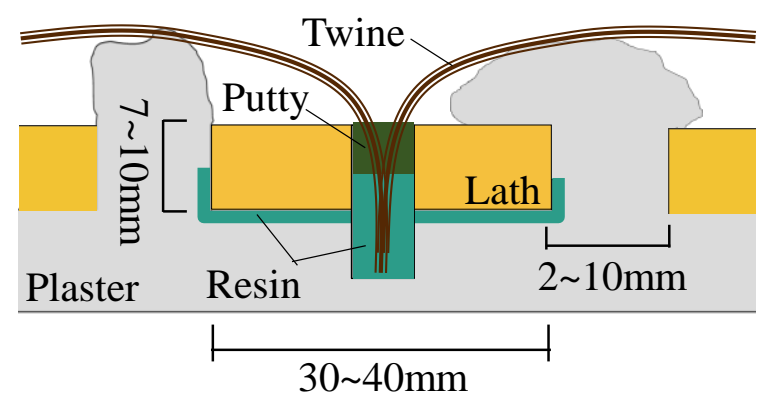

e)Improved cross section of plaster ceiling

Figure 3. Process of repairing lath plaster ceiling

\section{RESULTS AND DISCUSSIONS}

\section{Non-destructive testing of ceiling specimen}

The two ceilings of Morioka bank were compared to one another in regards to the abilities of the construction workers, surrounding environments, and materials used. Table 4 shows the results of a comparison of the two ceiling specimens. The space of the wooden lath of 1911 was more than 10mm length, and plaster keys were formed solidly. In addition, the timber around the lath were stable in both thickness and width. On the other hand, the specimen of the 1930s was two times as big as the 1911 specimen. Additionaly, the gaps of the wooden lath were less than $10 \mathrm{~mm}$ wide. Therefore, the plaster ceiling was heavy and there were significant influences to the plaster layer exfoliation. 
Table 4. The properties of Iwate Bank specimens

a) 1911 specimen

\begin{tabular}{|c|c|c|c|}
\hline \multicolumn{2}{|c|}{ Role of layer } & Thickness $(\mathrm{mm})$ & Material \\
\hline 1 & Lath & $9.5 \sim 10.5$ & Japanese cedar \\
\hline 2 & Plaster key & $3 \sim 4$ & plaster, fiber, sand (fewer) \\
\hline 3 & Fixing of twine & $6 \sim 8$ & plaster, fiber, sand \\
\hline 5 & Unevenness adjusting & $1 \sim 2$ & plaster, fiber, sand \\
\hline 5 & Finish plaster & 0.5 & plaster, fiber (fewer) \\
\hline
\end{tabular}

b) 1930s specimen

\begin{tabular}{|c|c|c|c|}
\hline \multicolumn{2}{|c|}{ Role of layer } & Thickness $(\mathrm{mm})$ & Material \\
\hline 1 & Lath & $9.0 \sim 11.0$ & Japanese cedar \\
\hline 2 & Plaster key & $2 \sim 3$ & plaster, fiber, sand (fewer) \\
\hline 3 & Fixing of twine & $8 \sim 10$ & plaster, fiber, sand \\
\hline 4 & $\begin{array}{c}\text { Unevenness adjusting- } \\
1\end{array}$ & 2 & plaster, fiber, sand (fewer) \\
\hline 5 & $\begin{array}{c}\text { Unevenness adjusting- } \\
2\end{array}$ & $4 \sim 5$ & plaster, fiber, sand \\
\hline 6 & Finish plaster & $1 \sim 3$ & plaster, fiber (fewer) \\
\hline
\end{tabular}

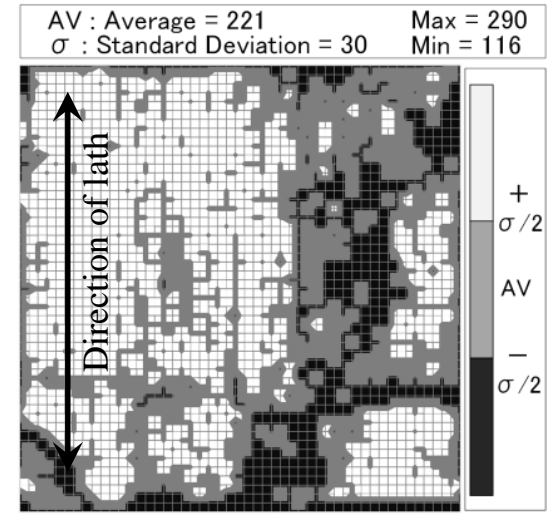

a) 1911

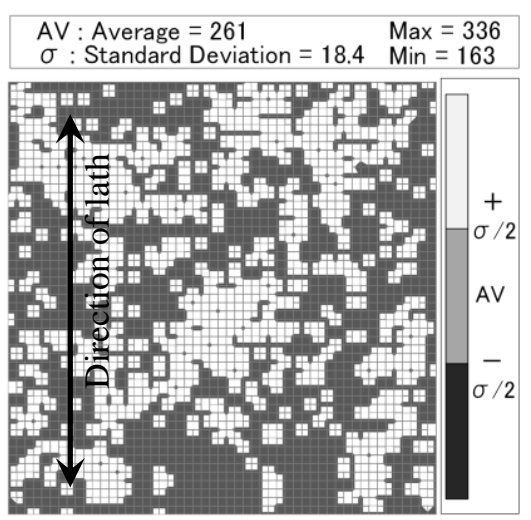

b) $1930 \mathrm{~s}$

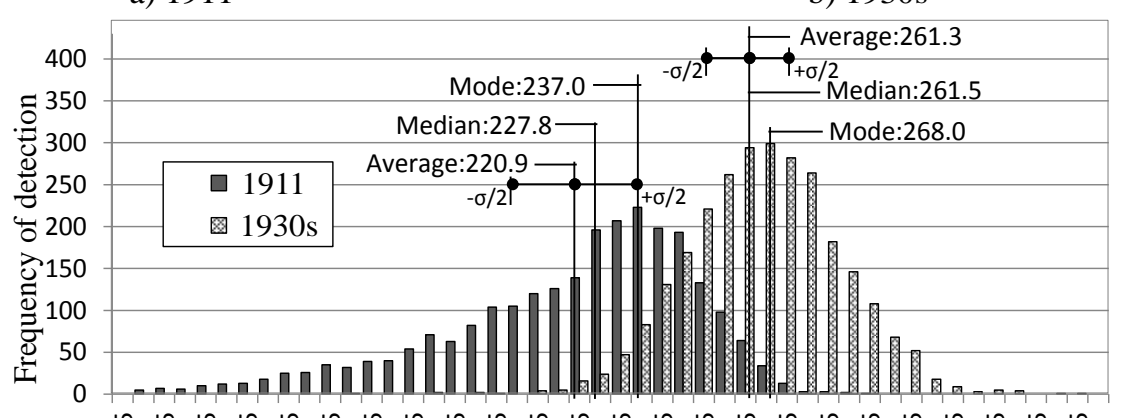

公 设 守 守 宑 守

*HLD = The mechanical impedance value by hammering test (non-destructive inspection)

c) Frequency detection of HLD

Figure 4. Results of non-destructive hammering test 
Figure 4 shows the results of the non-destructive hammering test. The color of figures a) and b) were classified by surface hardness of plaster ceiling. Figure c) shows a frequency distribution of surface hardness values of the two specimens. The strength of the ceiling at 1911 had a locally small part of plaster surfaces and was shown that the relative strength was smaller than average strength. The peak value of the strength of the 1911 was smaller than that of the 1930s. Thus, this means that the plaster of the ceiling had already been fragile, and when the peeling and falling of the plaster layer, the broken unit and particles were assumed to become small pieces. On the other hand, the hammering test results of the specimens from the 1930s were stable and small variability. The reason is that the thick plaster layer and high rigidity.

Influence on the strength of plaster Formulation. Figure 5 is shear strength of the plaster and fracture energy. Firstly, the maximum stress of the plaster was increased by about 20\%, and the fracture energy was increased to $250 \%$. The case of including small fibers was effective at increasing the shear stress, like a reinforced concrete rebar. Then, as for the plaster containing sand, the maximum stress was not increased, and the fracture energy was also reduced. As for the flexural strength, the plaster including the maximum amount of fiber was increased by $40 \%$ by increasing fiber contents, and the fracture energy of the sand was reduced by $27 \%$.
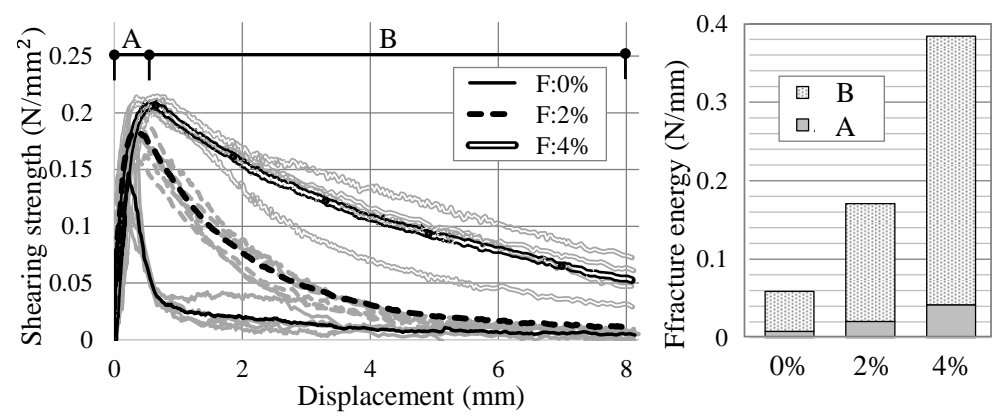

a) Shearing strength and fiber
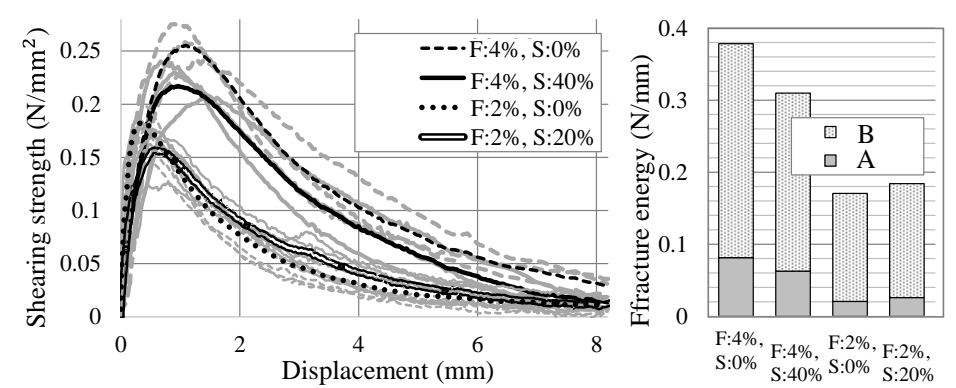

b) Shearing strength, sand and fiber
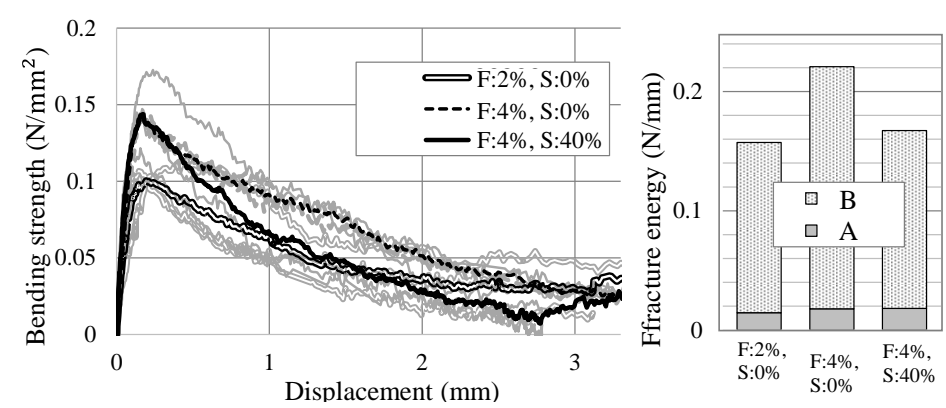

c) Bending strangth, sand and fiber

Figure 5. Relationship between plaster strength and mixture proportion 
Peel test of Plaster Layer. Figure 6 shows the relationship between breaking lord and width of gap of the lath. This test was performed in the test body that we prepared (See figure 2). Therefore, traditional members of Morioka Bank is not used for destructive testing. Breaking load was correlated with the width of the wooden lath clearance. In addition, the plaster containing sand, the breaking strength would tend to be strengthened. This can be explained from the result that the drying shrinkage of the plaster containing lots of sand is smaller than that of no sand type. The closer the length between the wooden lath and plaster, the plaster key would expect strong mechanical interlocking conditions. However, if the amount of sand is too large, the positive effectiveness was eliminated, the strength would be decreased.

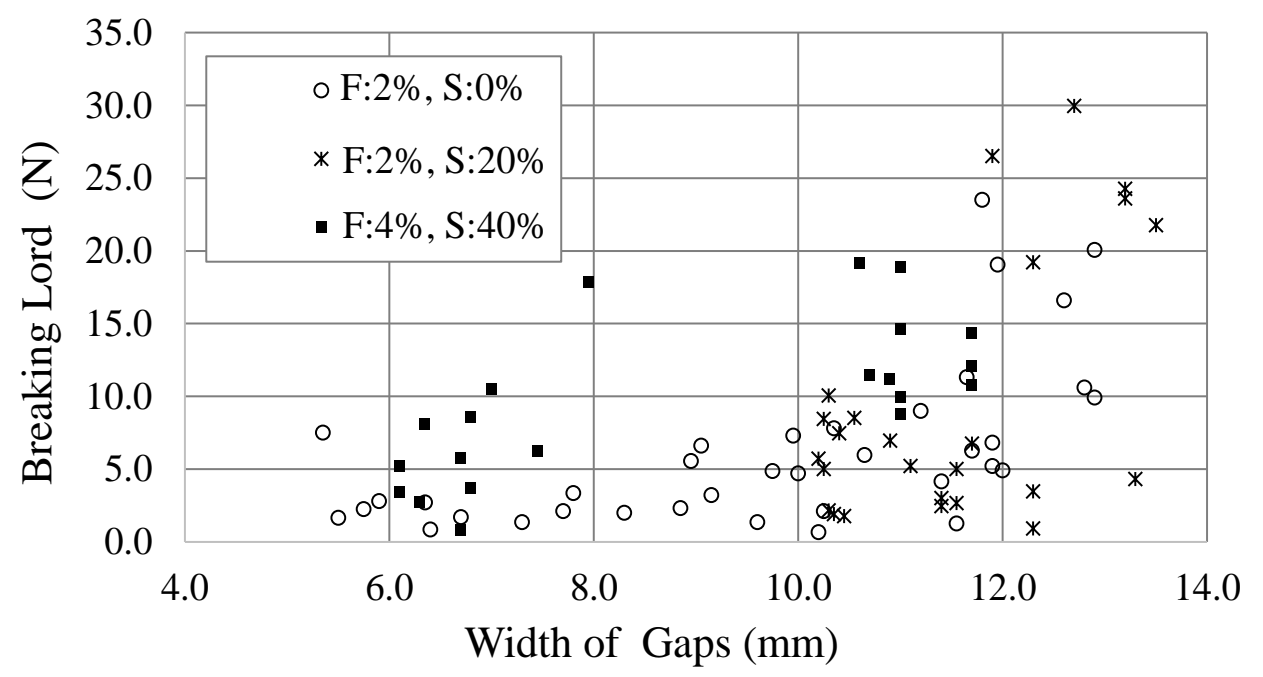

Figure 6. Breaking Lord of Lath and Plaster $(40 \times 40 \mathrm{~mm}$ Square, Just above the Gap $)$

\section{CONCLUSION}

The following general conclusions can be drawn from the study provided in the paper:

- It is presumed that proper maintenance and long life of the historic building is accomplished by evaluating health of the member.

- Our results showed that non-destructive soundness evaluation of wooden lath and plaster is reliable.

- The peeling strength of plaster is correlated with the width of the gap, and it is increased by including the sand.

- Injection of resin into the wooden lath and plaster to improve the peel strength. In addition, it does not change appearance. Therefore, this method is compatible with the repair of historic buildings.

\section{ACKNOWLEDGEMENTS}

This study was conducted as part of Grant-in-Aid for Basic research B (Yamamoto Hirokazu) of MOE and UDM Project of Kogakuin University. The authors express their gratitude to their financial support. 


\section{REFERENCES}

Kasai Y and others, Production Process and Bending/Compressive Strength of Wood-Chip Concrete with demolished-timber, Transaction of AIJ, No.473, pp.1-10, 1995 (in Japanese)

Oka K and Masaki.T, Life Cycle Management Strategy in consideration for Disaster Response of the Structure, Collected papers of JSMS Symposium on Concrete Structure Scenarios, Vol.14, pp.295-302, 2014 (in Japanese)

Oka K and others, Maintenance and Conservation Strategy for Building and constructed assets in Life Cycle Management, Collected papers of AIJ, pp.1359-1360, 2014 (in Japanese)

Sarja A, Structural Wood-Fiber Concrete, Concrete International, pp.45-49, 1989

Recommendations for Environmentally conscious Practice of Reinforced Concrete Buildings, Architectural institute of Japan, 2008

ISO13315,Environment Management of Concrete and Concrete Structures, Part 1 General Principle, 2012 